\title{
Drying of betel leaves (Piper betle L.): quality and drying kinetics
}

\begin{abstract}
This work studied the effects of drying temperature on the quality and drying kinetics of betel leaves (Piper betle L.). As the drying process applies heat on the product, this might lead to the degradation and decomposition of valuable phytochemicals within the herbs. In this study, the effect of drying temperature on the quality of dried leaves was studied by analyzing the change of major phytochemicals found in the leaves, which are hydroxychavicol and eugenol. The results indicate that the content of major compounds increased with temperature from 40 to $70^{\circ} \mathrm{C}$ but underwent decomposition when the leaves dried at $80^{\circ} \mathrm{C}$. Besides that, the drying kinetics for different drying temperatures also studied. The kinetics results show that the increase of drying temperature shortened the total drying time. Five thin-layer models were selected in describing the drying process of betel leaves. The logarithmic model was found to be the most suitable one.
\end{abstract}

Keyword: Drying kinetics; Eugenol; Hydroxychavicol; Piper betle L.; Thin-layer models 